\title{
Optimizasyon Tabanlı Adaptif Görüntü Mozaikleme Algoritmas1
}

\author{
Mehmet KARAKÖSE ${ }^{1}$, Hasan YETIŞ ${ }^{1}$, Taha MÜEZZINOĞLU ${ }^{1}$ \\ ${ }^{1}$ Frrat Üniversitesi Bilgisayar Mühendisliği Bölümü, Elazı̆̆ \\ mkarakose@ firat.edu.tr, h.yetis@ firat.edu.tr, tmuezzinoglu@ firat.edu.tr \\ (Geliş/Received: 02.02.2017; Kabul/Accepted:03.09.2017) \\ DOI: $10.17671 /$ gazibtd. 289344
}

\begin{abstract}
Özet- Görüntü işleme, dijital ortamdaki görüntüler üzerinde bir amaç doğrultusunda gerekli analizler veya değişikliklerin yapılmasına yönelik çalışmaları kapsamaktadır. Son zamanlarda görüntü işleme tekniklerinden en çok kullanılanlardan biri de ortak sahneleri içeren resimler üzerinde ișlem yapan ve bunları çakıştırarak birleștiren görüntü mozaikleme işlemidir. Bu çalışmada kendi kameramızdan elde ettiğimiz görüntüler üzerinde MATLAB ortamında görüntü mozaikleme işlemi gerçekleştirilmiştir. Görüntü mozaikleme için, özellik tabanlı görüntü mozaiklemenin temel adımları olan anahtar noktaların tespiti, bu noktaların eşleştirilmesi, hatalı eşleşmelerin elenmesi ve homografi tahmini uygulanmıștır. Uygulamada özellik çıkarımı için SIFT algoritması seçilmiş, elde edilen homografi matrisi yardımı ile gerekli dönüşüm işlemleri uygulanarak görüntü mozaikleme işlemi gerçekleştirilmiştir. Mozaikleme işleminin kalitesini artırmak adına optimizasyon yöntemi olan genetik algoritmadan yararlanılmışıtır. Uygulamada giriş görüntü sayıları ve mozaikleme parametreleri farklı seçilerek çeşitli karşıllaştırma işlemleri yapılımıştır.
\end{abstract}

Anahtar Kelimeler — Genetik algoritma, Görüntü işleme, Görüntü mozaikleme, Optimizasyon.

\section{Optimization Based Adaptive Image Mosaicing Algorithm}

\begin{abstract}
Image processing involves studies to make necessary analyzes or changes in an image aimed at digital images. One of the most recent use of image processing techniques is image mosaicking, which processes and combines images containing common scenes. In this study, we performed image mosaicing in the MATLAB environment on the images we acquired from our own camera. The key steps for feature-based image mosaicking which are detection of key points, matching of these points, elimination of mismatches and homography estimation are applied for image mosaicing. In the application, the SIFT algorithm was selected for feature extraction and image transformation was performed with the help of the obtained homography matrix. In order to increase the quality of the mosaic process, genetic algorithm, which is an optimization method, has been used. Various comparisons were performed by taking different input counts and by choosing different image mosaicing parameters.
\end{abstract}

Keywords - Genetic algorithm, Image processing, Image mosaicing, Optimization.

\section{GIRIŞ (INTRODUCTION)}

Görüntü işleme, görüntüler üzerinde bir takım işlemler yaparak, görüntüden bilgi veya yeni bir görüntü elde etme işleminin genel adıdır. Görüntü işleme teknikleri; bilgisayar türevi makineler tarafından, görüntüden anlam çıkarmak için kullanıldıkları gibi görüntüdeki gürültüleri eleme, görüntünün renk dengesini düzenleme ve daha yüksek çözünürlüklü görüntüler elde etme gibi görüntü iyileştirme işlemleri için de yaygın olarak kullanılırlar. Gelişen teknoloji ile birlikte günümüzde görüntü işleme yöntemlerinin birçok alanda kullanımları mevcuttur [1,2].

Günümüzde çalıșmalara en çok konu olan görüntü işleme uygulamalarından biri de görüntü mozaikleme olarak bilinen görüntü birleştirme işlemidir. Görüntü mozaikleme ortak noktaları bulunan veya belli noktaları çakışan iki veya daha fazla resmin belirli algoritma ve yöntemler vasıtasıyla birleştirilip daha büyük alanı kapsayan görüntü elde edilmesidir [3]. Görüntü mozaikleme yönteminde amaç görüntü kalitesini düşürmeden daha büyük alana ait bir resimler bütünü oluşturmaktır.

Görüntü mozaikleme düşük maliyetle daha yüksek çözünürlüğe sahip görüntüler elde etmede çok s1k kullanılırlar. Büyük bir sahneye ait tek bir görüntü karesi elde etmek için kameranın yeterince uzak bir konumda bulunması gerekmektedir. Kamera çalışma prensibine göre uzaktan alınan görüntüde daha büyük alanlar daha küçük pikseller ile ifade edildiğinden dolayı görüntüdeki 
detaylar kaybolur. Görüntü mozaikleme yöntemi sayesinde aynı alana ait daha yakından alınan görüntüler ile yüksek çözünürlüklü görüntüler elde etmek mümkün olmaktadır. Alınan bu görüntüler düz bir biçimde birbirine eklenebileceği gibi panoramik görüntü elde etmede de kullanılabilirler [4].

Literatürde görüntü mozaikleme ile ilgili yapılmış birçok makale ve tez çalışması mevcuttur. Divya, yüksek çözünürlüğe sahip geniş açılı manzara fotoğrafları elde etmek için görüntü mozaiklemede sıklıkla kullanılan özellik çıkarma, anahtar nokta eşleştirme, küme analizi ve dinamik programlama gibi genel yöntemlerin yanında birleşmiş görüntüyü yumuşatmak ve geçişleri belli olmayan görüntü elde etmek için ağırlıklı ortalama yöntemini de kullanmıştır. Kullandığı maskeleme ile Divya'nın yöntemi karanlık alanlarda etkili sonuçlar vermesine rağmen aydınlık alanlar için yetersiz kalmıştır [5]. Lin çalışmasında panoramik görüntüler elde edebilmek için görüntü mozaiklemeyi kullanmıştır. İlk önce lensten gelen bozulmaları gidermek için geriye dönük bölünme, sonra tutarlılığı sağlamak için silindirik izdüşümü yönteminden yararlanmıştır. Özellik tespiti için ölçekten bağımsız özellik dönüşüm yöntemi (SIFT) ve yanlış eşleştirmeleri elemine etmek için rastgele örneklerin fikir birliği (RANSAC) algoritmalarını kullanmıştır [4]. Elibol su altında alınan görüntülerin mozaiklenmesi işlemi için alt haritalama yöntemlerinden yararlanmıştır. Elibol çalışmasında özellik tanımlayıcıların eşleşmesine ve benzerliğine bağlı olarak alt haritaları oluşturabilmek için aglomeratif hiyerarşik kümeleme yöntemini kullanmıştır [6]. Patel yaptığ görüntü mozaikleme çalışmasında görüntüleri eşleştirmek için hızlandırılmış sağlam özellikler yöntemini (SURF) kullanmıştır. SURF özelliklerini eşleştirmek içinse karesel farkların toplamı (SSD) yönteminden yararlanmış, yanlış eşleştirmeleri RANSAC ile yok etmiştir. Ayrıca Patel çalışmasında Harris ile SURF yöntemlerini kıyaslamış ve SURF'un çok görüntülü görüntü mozaiklemede daha doğru sonuçlar verdiği kanaatine varmıștır [7]. Akram çalışmasında sistematik hastalıkların teşhisinde kullanılan ancak maksimum 45 derecelik açıyla alınabilen fundus görüntülerini birleştirerek tek bir görüntü elde etmeyi başarmıştır. Özelliklerin çıkarılması aşamasında Weber yerel tanımlayıcıları kullanmış, bu yöntemin performansını SURF, SIFT ve ASIFT gibi güncel algoritmalarla kıyaslamıştır [8].

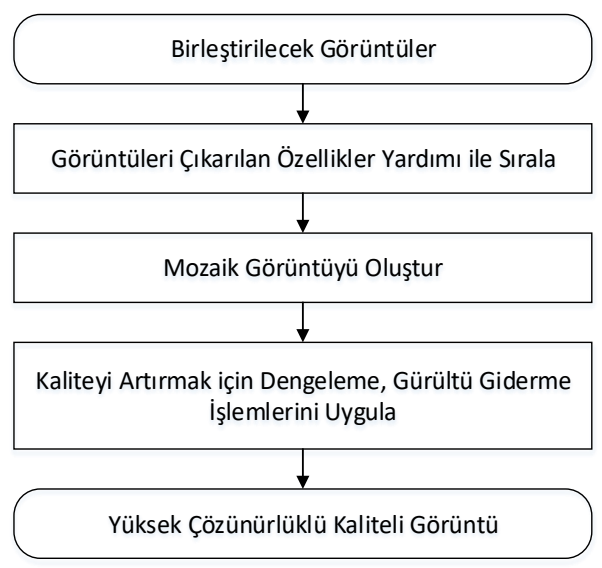

Şekil 1. Literatürde geçen genel mozaikleme adımları [9] (Basic mosaicing steps in literature)

Huang video gibi ardışık ve birbiri arasında çok az fark bulunan görüntülerin mozaiklenmesi üzerine çalışmış, bütün görüntü karelerini birleştirmek yerine aralarında kayda değer farklar bulunan görüntü karelerini mozaikleme işlemine tabii tutmuştur. Meydana gelebilecek hayalet görüntüleri engellemek için çalışmalar yapmıştır [10]. Lee çalışmasında özellik çıkarımı için SURF algoritmasını, eşleştirme işlemi için yönlü gradyan histogram (HoG) yöntemini ve yaklaşık en yakın komşuluk (ANN) algoritması kullanmış olup, hatalı eşleşmeleri elemek için RANSAC algoritmasından yararlanmıştır. Elde edilen görüntüdeki geçişlerin yumuşatılması işlemi çok bantlı harmanlama algoritması sayesinde gerçekleştirilmiştir [11]. Qiu görüntü mozaikleme işleminde görüntülerden sadece birinde yer alan nesnelerin sebep olduğu hayalet görüntüleri elemek için çalışmıştır. Yapılan çalışmada özellik çıkarımı için SIFT algoritması kullanılırken, hatalı eşleştirmeleri elemek için RANSAC algoritması kullanılmıștır. Optimum birleştirme çizgisini tespit etmek için ise dinamik programlama yöntemlerinden yararlanılmıştır [12]. Laraqui yaptığı çalışmada özellik çıkarma ve eşleştirme işlemini SIFT algoritmasını kullanarak gerçekleştirmiştir. Laraqui'nin çalışmasında farklı olarak hatalı eşleşmelerin elenmesinde voronoi diyagramından yararlanılmıştır [13].

Literatürdeki çalışmalar göz önüne alındığında genellikle görüntü mozaikleme işleminin adımları üzerinde geliştirmeler yapılarak daha iyi sonuçlar elde etmeye çalışıldığı gözlemlenmektedir. Oysa mozaikleme işleminde kullanılan parametrelerin optimize edilmesi de mozaikleme sonucu elde edilen görüntünün kalitesini etkilemektedir.

$\mathrm{Bu}$ çalışmada giriş görüntü sayıları ve görüntü mozaikleme parametreleri farklı alınarak çeşitli karşılaştırmalar yapılmıştır. Böylelikle parametre değerlerinin seçimlerinin mozaikleme işlemine etkileri vurgulanmıştır. Ardından kendi kameramızdan aldığımız görüntüler üzerinde, geliştirdiğimiz optimizasyon tabanlı adaptif görüntü mozaikleme yöntemi uygulanmıştır. 
Gerçekleştirilen yöntemde özellik çıkarımı için SIFT algoritmasından, hatalı eşleşmelerin elenmesi için ise RANSAC algoritmasından yararlanılmıştır. Görüntü mozaikleme parametreleri olan anahtar nokta sayısı, benzerlik oranı ve küme merkezi sayısının birleştirilen görüntünün kalitesine olan etkileri incelenmiştir. $\mathrm{Bu}$ parametrelerin en iyi birleştirme kalitesini sağlaması için alması gereken değerler, her görüntü mozaikleme problemi için farklı olacağından; yapılan çalışma ile bu parametrelerin optimum değerlerinin bulunması ve görüntü mozaikleme işleminin kalitesinin artırılması amaçlanmıştır. Geliştirilen yöntem MATLAB ortamında uygulanarak deneysel sonuçlar elde edilmiştir.

\section{GÖRÜNTÜ MOZAİKLEME (IMAGE MOSAICING)}

Görüntü mozaikleme, aynı sahneye ait birden fazla görüntünün içerdikleri ortak alanlara göre çakıştırılarak daha çok detay içeren tek bir görüntü elde edilmesi işlemidir [14]. Görüntü mozaikleme sayesinde görüntü alacağımız alanın resimlerini birbiriyle çakışacak şekilde parça parça çeker ve birleştirirsek daha kaliteli ve yüksek pikselli resimler elde edebiliriz. Genel olarak görüntü mozaikleme; düşük maliyetle daha kaliteli görüntü elde etmek, tek bir kameranın görüş açısına sığmayacak kadar büyük alanları fotoğraflamak, panoramik resimler oluşturmak ve bir video içerisindeki hareketli nesneleri silmek gibi çeşitli amaçlarla kullanılabilir.

Günümüzde farklı amaçlarla veya farklı yöntemlerle çalışmalara konu olmuş birçok görüntü füzyon tekniği mevcuttur $[15,16]$. Bu tekniklerden biriside bizimde kullanmış olduğumuz görüntü mozaikleme tekniğidir. Görüntü mozaikleme tekniğinin kullanıldığı başlıca alanlar şu şekilde gruplandırılabilir;

- Ak1llı Sistemler ve Robotlar (Kamera sistemleri)

- Tibbi Uygulamalar (Bilgisayar destekli cerrahi)

- Askeri Uygulamalar (İnsansız hava araçları vb.)

- Tarımsal Uygulamalar (Tarımsal arazi planlaması)

- Coğrafi Uygulamalar (Haritalama vb.)

Birleştirilecek görüntülerin sayısından bağımsız olarak, görüntü mozaikleme işlemi her adımda sadece iki resim arasında gerçekleşir [17]. Resimlerden bir tanesi referans, diğeri ise hedef görüntü olarak adlandırılır. Hedef görüntü ve referans görüntüdeki eşleşmiş noktalar çakışacak biçimde hedef görüntü yeniden şekillendirilir. Yeniden şekillendirilen görüntü referans görüntüye eklenerek daha büyük bir resim elde edilmiş olunur (Şekil 2). Elde edilen görüntü bir sonraki aşamada referans görüntü olarak kullanılabilir.

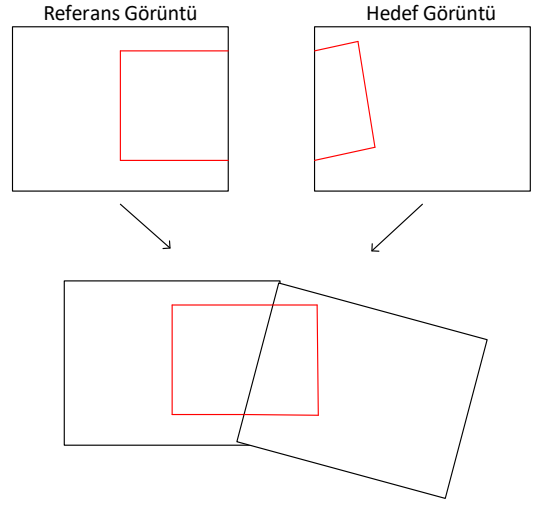

Şekil 2. Görüntü mozaikleme işlemi [3] (Image mosaicing process)

Görüntü mozaikleme için iki boyutlu uzayda ve frekans uzayında uygulanmak üzere yöntemler geliştirilmiştir [18]. Uzay domaininde uygulanan yöntemler kendi içerisinde alan tabanlı ve özellik tabanlı olmak üzere iki kısımda incelenebilir. Alan tabanlı yöntemler, iki resimdeki alanları renk yoğunluklarına göre eşleştirdiğinden; boyut değişimleri, 1şık değişimleri ve pozisyon değişimleri alan tabanlı yöntemlerin çalışmasını ciddi derecede olumsuz bir biçimde etkilemektedir. Bu çalışmada yararlanılan ve özellik tabanlı yöntemler kategorisinde yer alan ölçekten bağımsız özellik dönüşüm (SIFT - Scale Invariant Feature Transform) yöntemi bu dezavantajları ortadan kaldırmaktadır [19].

Özellik tabanlı görüntü eşleștirmede öncelikle giriş görüntülerine ait anahtar noktalar tespit edilir ve bu noktalara ait özellikler çıkartılır. Bu sayede iki resim arasında tüm piksellerin karşılaştırılması yerine sadece karakteristik bölgelerin karşılaştırılması yapılır. Özellikler çıkarıldıktan sonra özellikleri bakımından benzerlik gösteren noktalar birbiri ile eşleştirilir, bu sayede resimler arasındaki ilişki kurulmuş olunur. Çıkarılan özellikler görüntüdeki renk geçişleri ile doğrudan alakalı olduğundan, algoritmamız aynı geçişlere sahip bölgeleri aynı bölge gibi görecektir. Sonuç olarak istenmeyen eşleşmeler de meydana geleceğinden dolayı, hatalı eşleşmelerin elenmesi gerekir. Bu yönteme göre eşleşme olarak kabul edilen bölgelerin geometrik olarak diğer noktaların düzenine ters düşmesi durumunda aykırı nokta olarak belirlenir ve işleme alınmaz. Elde kalan eşleşmelerden faydalanarak homografi tahmini yapılır ve elde edilen bu matris kullanılarak resim eğilip bükülür. Son olarak aynı düzlemde gösterilen görüntülerin üst üste gelen kısımlarındaki renk farklılıklarını ortadan kaldırmak için renklerde harmanlama yapılır [20]. Özellik tabanlı görüntü mozaikleme adımları Şekil 3 'te verilmiştir. 


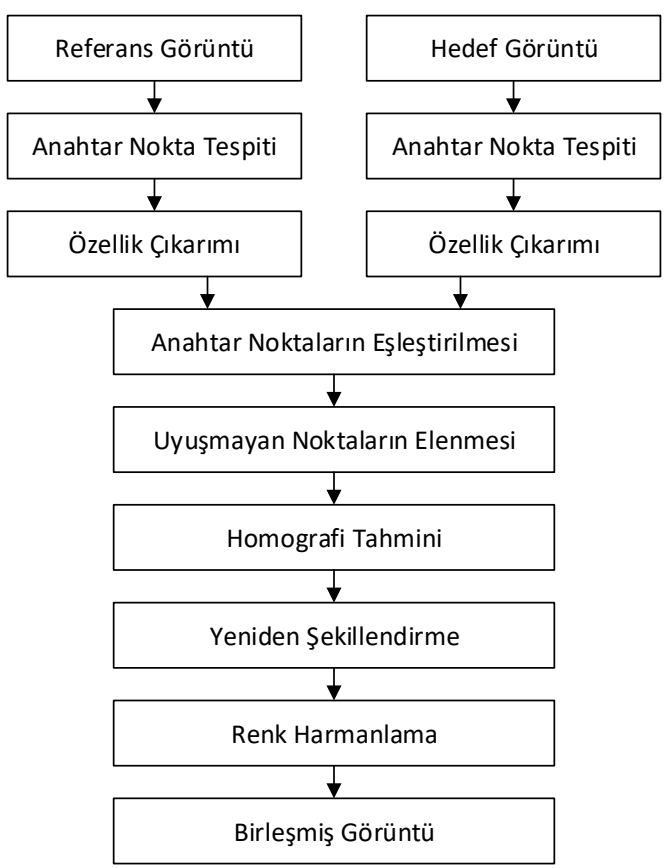

Şekil 3. Özellik tabanlı görüntü mozaikleme adımları [20] (Steps of feature-based image mosaicing)

\section{1. Özellik Çıkarımı (Feature Extraction)}

Görüntü mozaiklemede, özellik çıkarımının ilk aşaması olarak anahtar noktaların tespiti işlemi gerçekleştirilir. İki görüntünün kıyaslanma işlemi piksel bazında bütün pikseller için gerçekleştiğinde ortaya büyük hesaplama maliyeti çıkmaktadır. Bu yüzden resimde yer alan nesnelerin kenar, köşe veya kabarcık gibi karakteristik bölgeleri tespit edilerek, sadece bu bölgeler üzerinden kıyaslama ve eşleştirme işlemi yapılmaktadır [21]. İki görüntü arasındaki benzerliğin hesaplanması için anahtar noktalara ait özelliklerin bilinmesi gerekir. Görüntünün karakteristik yapısını, özellik haritasını çıkarmak için gerekli bir adımdır. Anahtar nokta tespiti için birçok algoritma önerilmiştir. Harris [22], SIFT [23], Susan [24], Canny [25], Kitchen-Rosenfeld [26] algoritmaları bunlardan bir kaçıdır.

Köşe bulma algoritması olan Moravec [27], komşu pikseller arasındaki değer farkını temel alarak köşe tespiti yapan ilk algoritmadır. Moravec yöntemi üzerine iyileştirmeler yapılarak Harris kenar bulma algoritması geliştirilmiştir. Susan yöntemi ise dairesel bir alan içerisinde kalan piksellerin değerlerinin karşılaştırmasına dayalı bir kenar ve köşe bulma algoritmasıdır. Bu çalışmada kullanmış olduğumuz SIFT algoritması, diğer algoritmalardan avantajlı olarak, kontrast değerinden, ortamdaki ışık oranından ve kamera açısından diğerlerine göre daha az etkilenen bir yöntemdir.

\subsubsection{SIFT Algoritması (SIFT Algorithm)}

Anahtar nokta tespiti için kullanılan SIFT operatörünün en önemli özelliği, görüntünün boyutundan, 1 şık miktarından, kamera açısının değişiminden, kontrast ya da gürültüden etkilenmemesidir [28]. Bir görüntünün farklı sahneleri arasındaki değişmeyen özellikleri ayıklamak, resimlerdeki farklılıkları ve resmin herhangi bir nesneyi içerip içermediği gibi konuları gerçekleştirmek için geliştirilmiştir. Dört temel aşamadan oluşur.

- Uç değer noktaların belirlenmesi

- Anahtar noktaların tespiti

- Yönelim açısı ve büyüklüğünün hesaplanması

- Anahtar nokta tanımlayıcılarının elde edilmesi.

\subsubsection{Uç Değer Noktaların Belirlenmesi}

Görüntü üzerindeki uç değer noktaların konumlarını tespit etmek için kademeli bir filtreleme yaklaşımı uygulanır. Ölçek uzayının belirleme işleminde Gauss farkı (DoG), yönteminden yararlanılmıştır. Bu yönteme göre öncelikle görüntünün farklı sigma değerleri için gauss filtresine tabii tutulmuş halleri elde edilir. Gauss farkı yöntemi ile uç noktalar daha belirgin hale getirilmiş olunur (Şekil 4). $\mathrm{Bu}$ sayede görüntüdeki karakteristik noktalar ön plana çıkmış olur.

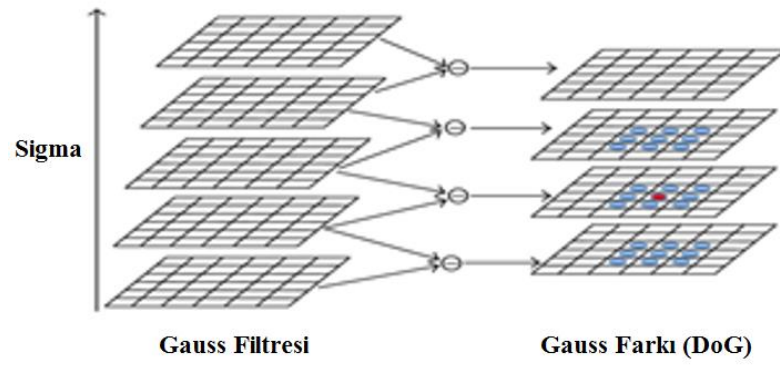

Şekil 4. Gauss farkı yöntemi [29] (Difference of Gaussian method)

\subsubsection{Anahtar Noktalarin Belirlenmesi}

Uç noktaların tespiti işlemi sonucu, gerçekte uç nokta olmayan birçok nokta da uç nokta olarak belirlenmiş olur. Bunlar gibi kararlı olmayan zayıf uç noktaların nihai anahtar noktalar kümesine dahil edilmemesi gerekir. Bunun için bazı filtrelemeler ve eşiklemeler yardımı ile kontrastı düşük ve zayıf uç noktalar elenir (Şekil 5).

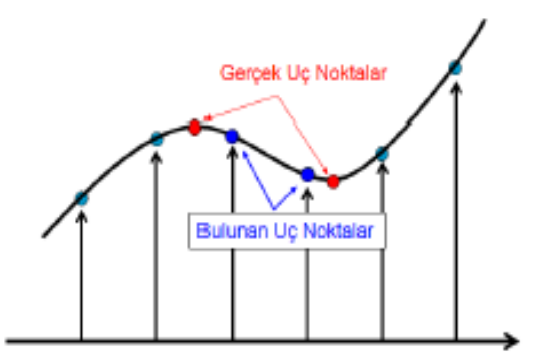

Şekil 5. Tespit edilen zayıf ve gerçek uç noktalar [30] (Detected weak and real interest points) 


\subsubsection{Yönelim Tespiti}

Bir önceki adımda bulunan her anahtar noktaya ait yönelim açısı ve büyüklüğü hesaplanır. Resimdeki her anahtar noktanın tüm komşu pikselleri için bu hesap yapılır. Her anahtar nokta adayının etrafinda bir alan seçilir, yumuşatılmış görüntü (L) üzerinde bu değerler hesaplanır. $m(x, y)$ yönelim büyüklügü formülü (1) ile, $\theta(\mathrm{x}, \mathrm{y})$ yönelim açısının formülü (2) ile verilmiştir [31].

$\sqrt{(L(x+1, y)-L(x-1, y))^{2}+(L(x, y+1)-L(x, y-1))^{2}}$

$Q(x, y)=\tan ^{-1} \frac{(L(x+1, y)-L(x-1, y))}{(L(x, y+1)-L(x, y-1))}$

\subsubsection{Anahtar Nokta Tanımlayıcıların Bulunması}

Yönelim açıları ve büyüklükleri hesaplanan anahtar noktaların etrafındaki tanımlayıcıları tespit edilir. Anahtar noktanın 16x16'lık komşularını içeren 4x4'lük bir alan içerisinde gerçekleşen tanımlayıcıların tespiti işlemi Şekil 6 ile verilmiștir. Bu alt alanlarda, 45'er derecelik dilimler dahilinde aynı bölgeye denk gelen yönelim büyüklükleri toplanarak histogram değerleri oluşturulur. Sonuç olarak $4 \times 4$ 'lük karenin her biri 8 vektörel büyüklüğe sahiptir ve elde edilen SIFT özelliği 128 boyutunda bir vektördür.

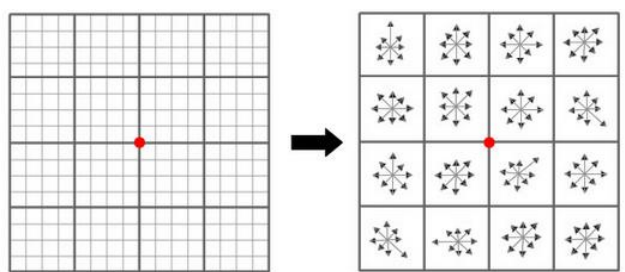

Şekil 6. Anahtar nokta tanımlayıcılarının bulunması (Detection of interest point descriptors)

\subsection{Görüntü Eșleștirme (Image Registration)}

Görüntü eşleştirme, anahtar nokta özelliklerinin tespiti yapıldıktan sonra tespit edilen anahtar noktaları birbiri ile eşleştirmek için kullanılır. İki görüntü üzerinde tespit edilen noktalar, özelliklerinin benzerliklerine göre birbirleri ile eşleştirilir. $\mathrm{Bu}$ işlem ile farklı görüntülerde benzer ya da aynı nesneler tespit edilmiş olunur. Görüntü eşleştirmede söz konusu olduğunda temel olarak iki farklı yöntem karşımıza çıkar. Bunlar özellik tabanlı eşleștirme ve korelasyon ile eşleştirmedir.

Özellik tabanlı eşleştirmede, ilk görüntüdeki her anahtar nokta ile ikinci görüntüdeki tüm anahtar noktalar karşılaştırılır. İki görüntüde aynı nesneye ait görüntüler için birebir aynı özellik elde etmek pek mümkün olmayacağından, eşleştirme yaparken birebir eşleştirme yerine bir eşitsizlik kısıtlaması kullanılır. İkinci yöntem olan korelasyon ile eşleştirmede ise, verilen koordinatlar ile iki görüntü arasındaki ilk keyfi eşleştirme bulunur. Sonraki amaç, eşleştirme işlemi için ikinci görüntüdeki anahtar noktaya karşılık gelen özelliği bulmaktır. İkinci görüntüdeki her anahtar noktanın karşılaştırılması zaman açısından pahalı bir yöntemdir. Bunun yerine korelasyon tabanlı bir teknik olan korelasyon penceresi oluşturulur. Benzerlik ölçütü olarak kosinüs benzerliği veya Öklit benzerlik kriterleri kullanılır. Kullanılan geliştirme aracının hangisinde daha iyi performans gösterdiği belirlenir ve buna göre seçim yapılır [30].

\subsubsection{Kosinüs Benzerlik Ölçütü ile Görüntü Eşleştirme}

Bu yöntemde, anahtar noktaların yönelim büyüklükleri ve ağırlıkları parametre olarak alınır. Alınan bu büyüklükler birer vektör oluşturur. $\mathrm{Bu}$ vektörlerin noktasal çarpımlarının, vektörel çarpımlarına oranı bize kosinüs benzerlik değerini verir (3).

$$
\cos (V 1, V 2)=\frac{\operatorname{dot}(\mathrm{V} 1, \mathrm{~V} 2)}{\|\mathrm{V} 1\| \mathrm{x}|| \mathrm{V} 2 \|}
$$

Etkili bir eşleştirme için en yakın komşu mesafesi karşılaștırılması yapılır [32]. Benzerlik oranı, belirlenen eşik değerinin altında olan eşleştirmeler yok sayılarak yanlış eşleştirmeler ayıklanır. Sonuç olarak iki resim arasında benzerlik gösteren noktalar eşleşmiş olarak kabul edilir (Şekil 7).

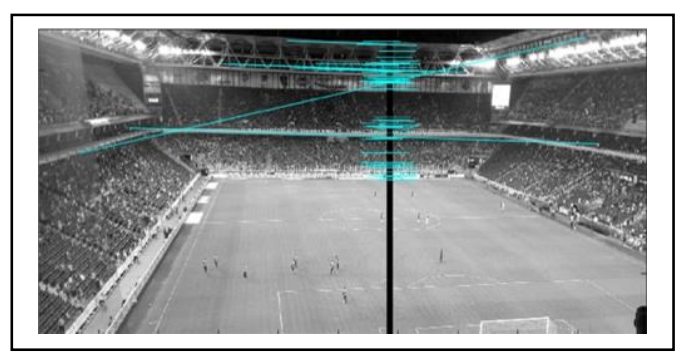

Şekil 7. İki görüntü arasındaki eşleşen anahtar noktalar (Matched interest points between the two images)

\subsection{Eşleşmiş Noktalar İle Homografi Tahmini}

Eşleştirme işlemi sonucunda iki görüntüde de ortak olan nesneler belirlenmiş ve eşleştirilmiş olunur. Görüntü birleştirme işlemi için tespit edilen ortak nesnelerin birbiri ile çakıştırılacak şekilde ayarlanması için görüntülerin aynı düzleme düşürülecek şekilde yeniden düzenlenmesi gerekmektedir. Homografi adi verilen matris sayesinde bir görüntüdeki ilgili koordinatların dönüştürülerek diğer görüntüdeki ilgili koordinatlara denk gelmesi sağlanır.

\subsubsection{Aykırı Eşleşmelerin Elenmesi}

Hatalı eşleştirmeler oluştuğunda iki resmi aynı düzleme düşürmeye çalıştığımızda problemlere yol açacaktır. Bundan dolayı edilen uyuşmayan noktaların elenmesi gerekmektedir. Dönüşüm parametrelerini tahmin etmede kullanılan RANSAC algoritması, her adımda rastgele 
verileri kullanarak en iyi sonuca ulaşmaya çalışan iteratif bir yöntemdir [33]. Bu yöntem ile muhtemel hatalı eşleşmelerin eleme işlemi gerçekleştirilir.

Genetik algoritmalar, destek vektör makineleri, bulanık küme sinıflandırıcıları, K-NN gibi yöntemler örnek tabanlı sınıflandırma yöntemleri arasında yer almaktadır. $\mathrm{Bu}$ çalışmada örnek tabanlı sınıflandırma yöntemlerinden olan K-NN sınıflandırma yöntemi kullanılmıştır. K-NN, kendisine parametre olarak gelen küme merkezi sayısına göre verilerin bu kümelere ait olup olmadığını tespit eden bir yöntemdir. Hatalı eşleştirmelerden etkilenmemek adına, aykırı verileri farklı bir kümeye atarak bunları göz ardı etmesi sonucun daha doğru üretilmesi açısından avantajlar sağlamaktadır. Sonuçta aykırı noktalardan elenen anahtar noktalar ile homografi tahmininde bulunarak dönüşüm işlemi için altyapı hazırlanmış olunur.

\subsubsection{Homografi Tahmini}

Homografi hedef görüntüdeki anahtar noktaları, referans görüntüde eşleştikleri anahtar noktalar ile aynı düzleme düşürmeye yarar. Dönüşümü yapılacak olan görüntüdeki pikseller homojen gösterim ile ifade edilir. H Homografi matrisi yardımı ile $\left(X_{1}, Y_{1}\right)$ noktasının yeni konumun $\left(X^{\prime}, Y^{\prime}\right)$ belirlenmesi için gerekli işlemler sırası ile (4), (5) ve (6) ile verilmiştir.

$$
\begin{gathered}
{\left[\begin{array}{lll}
h_{11} & h_{12} & h_{13} \\
h_{21} & h_{22} & h_{23} \\
h_{31} & h_{32} & h_{33}
\end{array}\right]\left[\begin{array}{c}
X_{1} \\
Y_{1} \\
1
\end{array}\right]=\left[\begin{array}{c}
X_{n} \\
Y_{n} \\
Z_{n}
\end{array}\right]} \\
X^{\prime}=\frac{X_{n}}{Z_{n}}=\frac{h_{11} X_{1}+h_{12} Y_{1}+h_{13} Z_{1}}{h_{31} X_{1}+h_{32} Y_{1}+h_{33} Z_{1}} \\
Y^{\prime}=\frac{Y_{n}}{Z_{n}}=\frac{h_{21} X_{1}+h_{22} Y_{1}+h_{23} Z_{1}}{h_{31} X_{1}+h_{32} Y_{1}+h_{33} Z_{1}}
\end{gathered}
$$

Homografi tahmini işlemi her nokta için (5) ve (6)'daki eşitliği en az hata ile sağlayan $h$ parametrelerinin tespit edilmesi ile gerçekleşir. Elde edilen bu matris sayesinde görüntü eğilip bükülerek yeniden şekillendirilir (Şekil 8).

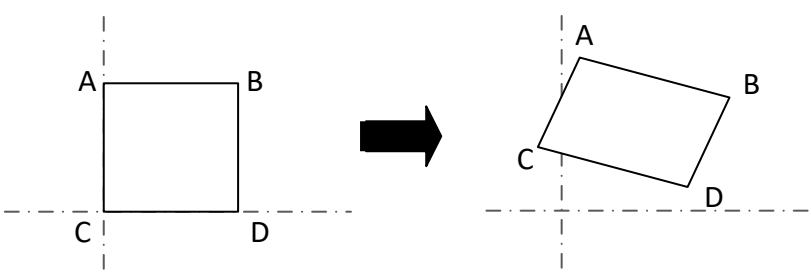

Şekil 8. Homografi dönüşümü (Homogaphy transform)

\subsection{Görüntü Birleştirme}

Çeşitli algoritmalar sonucu elde edilen homografi matrisinden yararlanarak görüntülerdeki eşleşmiş alanların üst üste çakıştırılmasını sağlayan son aşamayı oluşturur. Dönüştürülen görüntülerin aynı düzlem üzerinde çizdirilmesi ile görüntü birleştirme işlemi gerçekleştirilir.

Homografi matrisinin uygulanmasının ardından, giriş ve referans olarak alınan görüntüler birbirine göre hizalanır. Boyut kontrol edilir, eğer boyutları eşit değil ise, boyutu eşitlemek adına boş alanlar siyah gösterilir ve iki görüntünün de aynı düzlemde gösterilmesi ile mozaikleme işlemi gerçekleştirilmiş olunur. Kameraların açısı, özelliği ve konumu dolayısı ile örtüşen sahnelerin iki görüntüdeki kontrastları farklı olabilir. $\mathrm{Bu}$ olumsuzluğu gidermek adına, çakıştırılacak bölgelerin kontrast değerlerinin ortalaması alınması veya yüksek kontrastlı alanların kontrast açma işlemine tabi tutulması gibi yöntemler mevcuttur [34]. Kontrast farkının mozaiklenen görüntü üzerindeki etkisi Şekil 9'da verilen mozaikleme örneğinde gözlemlenebilmektedir.
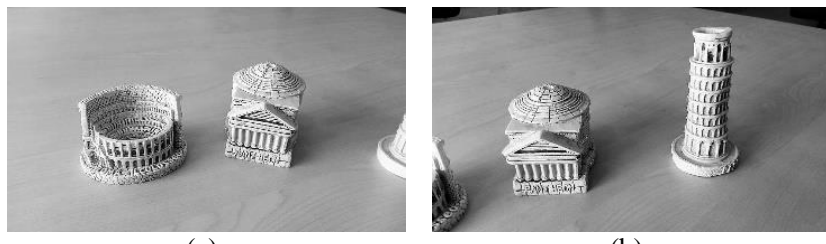

(a)

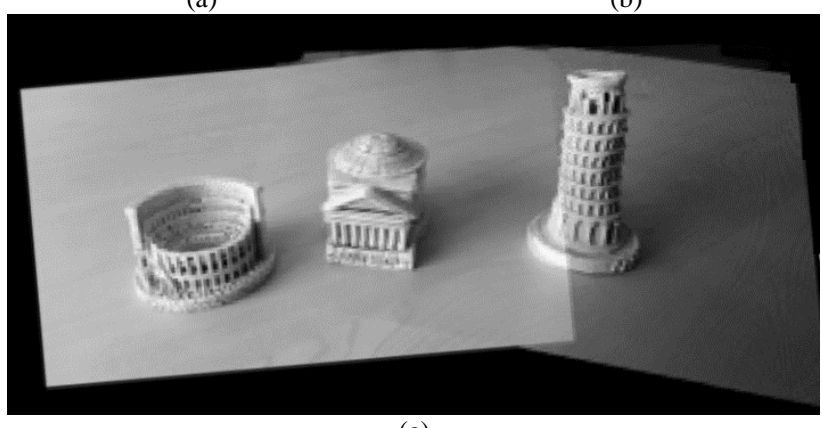

(c)

Şekil 9. Renk harmanlama yapılmadan görüntü mozaikleme sonucu: (a),(b) giriş; (c) çıkış görüntüsü (Mosaicing result without blending operation: (a),(b) inputs; (c) output)

\section{3. ÖNERİLEN YÖNTEM (PROPOSED METHOD)}

Şekil 3'te görüleceği üzere mozaiklenmesi gereken görüntüler üzerinde ilk olarak uygulanması gereken adım özellik çıkarma adımıdır. Bu adımda görüntülerdeki tüm pikselleri tek tek kontrol etmek yerine sadece karakteristik bölgelerin/piksellerin kontrol edilmesi için görüntü üzerindeki karakteristik bölgeler tespit edilir. Birleştirilecek görüntüler üzerinde anahtar nokta tespiti kenar, köşe veya kabarcık denilen noktalarının bulunması ile gerçekleştirilmektedir. Anahtar noktaları bulunun görüntüler üzerinde çakışan noktaların bulunması için görüntü eşleştirme işlemi yapılır. Görüntü eşleştirme, anahtar nokta özelliklerinin tespiti yapıldıktan sonra bu anahtar noktaların eşleştirilmesi amacı ile kullanılır. Görüntü eşleştirme işleminde ortak noktaların 
belirlenmesi için ilk önce KNN algoritması kullanılarak sınıflandırma işımi yapılır. Birleştirilecek görüntüler üzerinde çakışan ortak noktalar bulunup görüntüler eşleştirildikten sonra, bulunan noktalar içerisindeki aykırı noktaların tespiti için RANSAC algoritması uygulanır. Aralarında eşleşmiş anahtar noktaları bulunan görüntülerin aynı düzlemde gösterilmesi gerekmektedir.

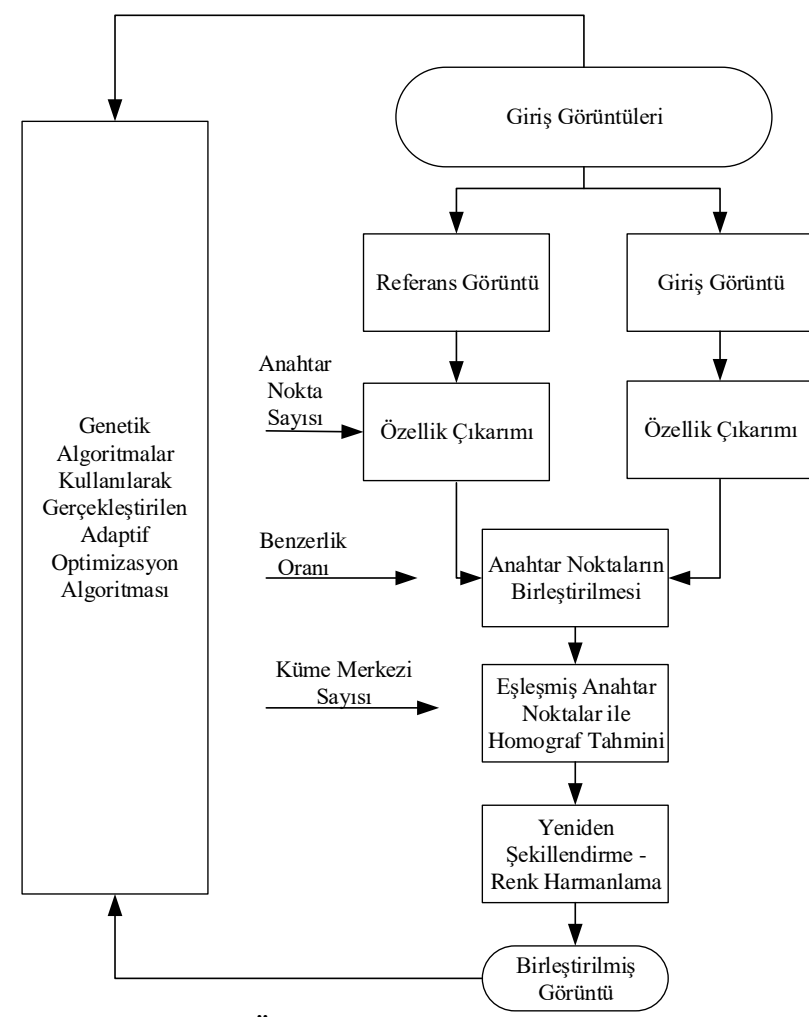

Şekil 10. Önerilen yöntemin blok diyagramı (Block diagraam of proposed method)

Gerçekleştirilen uzaysal dönüşüm ile giriş görüntüsündeki sahnelerin referans görüntüdeki yerlerine yerleştirilmesi sağlanır. Aykırı örneklerden arındırılmış görüntü matrisleri üzerinde yapılan homografi tahmini kullanılarak benzerlik gösteren sahnelerin çakıştırılması işlemidir. Görüntülerdeki benzer sahnelerin çakıştırılması için gereken dönüşüm işlemi, hesaplanan homografi matrisinin görüntüdeki bütün piksellere uygulanması ile gerçekleştirilir.

Son olarak yeniden şekillendirme (warping) ve renk harmanlama (blending) işlemleri sonucunda görüntüler birleştirilir. Yeniden şekillendirme işlemiyle birleştirilecek görüntülerden biri taban (referans) görüntü olarak seçilir ve görüntüler üzerinde örtüşen noktalara göre diğer görüntülere koordinat düzleminde döndürme işlemi uygulanır. Döndürme işlemi gerçekleştirildikten sonra görüntüler birleştirilir.

Çakışan kısımları bulunan görüntüler birleştirildikten sonra, görüntülerin çakışan kısımlarındaki birleştirme işleminin belli olmaması için, bu kısımlardaki pikseller üzerine renk harmanlama işlemi uygulanır. Renk harmanlama işlemi; mevcut örtüşen piksellerdeki bozukluğunu gidermek için piksellerdeki ağırlıklı ortalama renk değerlerini kullanarak, piksellerin karıştırılmasını sağlamaktadır.

\section{DENEYSEL SONUÇLAR (EXPERIMENTAL RESULTS)}

Yüksek çözünürlüğe sahip ideal resimler üzerinde görüntü mozaikleme uygulaması test edilmiştir. Giriş görüntülerinin çözünürlüğü ne kadar yüksek olursa anahtar nokta sayısı bununla orantılı olarak artmaktadır. Anahtar nokta sayısının çok olması olumsuz etkileri ortadan kaldırmaktadır. Yani anahtar nokta sayısının düşmesi ve artması doğruluk oranını etkilese de, kabul edilemez sonuçlar doğurmasına neden olmamaktadır.

Benzerlik oranı, tespit edilen anahtar noktaların belirli bir fark toleransı dahilinde eşleștirilmesi için kullanılan bir kriterdir. Benzerlik oranının yüksek tutulması birbirine daha çok benzer eşleşmelerin elde edilmesine sebep olur. Ancak bu şekilde elde edilen eşleşme sayısında azalma meydana gelir. Eşleşme sayısının yetersiz derecede az olması, anahtar nokta örneklerin siniflandırılmasındaki başarısına ve bu da dolayısıyla birleştirme işleminin kalitesine olumsuz etkilerde bulunmaktadır. Anahtar nokta sayısının fazla olduğu yüksek çözünürlüklü görüntülerde benzerlik oranının düşük olması, homografi tahmini için yine yeterli sayıda eşleşmenin sağlanmasına mani olmayacağından dolayı, bu tarz görüntülerde etkisi daha azdır. Ancak tespit edilen anahtar nokta sayısının az olduğu düşük çözünürlüklü görüntülerde bu oran daha büyük bir önem arz etmektedir.

Toplam küme merkezi sayısı eşleştirmenin doğruluğunu, dolayısı ile mozaikleme işleminin kalitesini etkileyen bir başka faktördür. Eşleşen anahtar noktaların, dışardan girilen bu parametreye bağlı olarak kümelendirilmesi işleminden sonra dönüşüm işlemi, tespit edilen küme merkezleri doğrultusunda gerçekleştirilir. Çok sayıda eşleşme olması durumunda küme merkezi sayısı fazla seçilebilir, ancak az sayıdaki eşleşmeler için yüksek bir sayı seçilmesi hatalı sınıflandırmalara neden olacağından dolayı görüntü mozaikleme işleminin kalitesini olumsuz etkilemektedir.

Uygulama sonuçları; aşağıdaki parametreler esas alınarak Tablo 1'de görüntülenmiştir.

- A: Anahtar nokta sayıs1,

- B: Benzerlik oranı,

- $\quad \mathrm{K}$ : Küme merkezi sayısı,

- S: Standart,

- $\quad$ S+: Standart üstü,

- S-: Standart alt1. 
Standart için belirlenen varsayılan değerler: $\mathrm{AS}=0.85$, $\mathrm{BS}=0.6, \mathrm{KS}=5$ 'tir.

Zaman ve doğruluk açısından en iyi çözüm aranırken, uygulama alanının kriterlerine göre değerlendirme yapılarak, bu parametreler şekillendirilebilirler. Yüksek çözünürlüklü resimlerde örtüşen sahne büyüklüğü de fazla olunca, anahtar nokta sayısı, benzerlik oranı ve küme merkezi gibi kriterler farklı sonuçlar doğurmamaktadır.
Tablo 1'den elde edilen zaman ve doğruluk oranı kriterlerine göre, en iyi çözümler dizisi ve uygulama çıktıları Tablo 2'de ve Tablo 3'te verilmiştir. Bu farklı parametreler için görüntü mozaikleme Tablo 2'de 2 ile 5 arasında giriş görüntüsü üzerinde; Tablo 3 'te ise videonun çerçeveleri arasında uygulanmıştır. Mozaikleme işlemi için geçen süreler tablolarda belirtilmiştir.

Tablo 1. Farklı anahtar nokta sayısı miktarı, benzerlik oranı ve küme merkezi sayısı için karşılaştırmalar (Comparison of the stitching performance for different number of interest points, the similarity rate and the number of cluster centers)

\begin{tabular}{|c|c|c|c|c|c|c|c|c|}
\hline \multirow[b]{2}{*}{$\mathbf{A}$} & \multirow[b]{2}{*}{ B } & \multirow[b]{2}{*}{$\mathbf{K}$} & \multicolumn{2}{|c|}{ İki Görüntü } & \multicolumn{2}{|c|}{ Üc Görüntü } & \multicolumn{2}{|c|}{ Beş Görüntü } \\
\hline & & & $\begin{array}{c}\text { Birleşme } \\
\text { Süresi (sn) }\end{array}$ & $\begin{array}{c}\text { Doğruluk } \\
\text { Oranı }\end{array}$ & $\begin{array}{c}\text { Birleşme } \\
\text { Süresi (sn) }\end{array}$ & $\begin{array}{c}\text { Doğruluk } \\
\text { Oranı }\end{array}$ & $\begin{array}{c}\text { Birleşme } \\
\text { Süresi (sn) }\end{array}$ & $\begin{array}{c}\text { Doğruluk } \\
\text { Oranı }\end{array}$ \\
\hline AS & $\mathrm{BS}$ & $\mathrm{KS}$ & 60,79 & Normal & 142,71 & Normal & 182.70 & Normal \\
\hline AS & BS & $\mathrm{KS}+$ & 61.82 & İyi & 144.13 & İyi & 190.32 & İyi \\
\hline AS & BS & KS- & 62.42 & Normal & 138.78 & Normal & 180.94 & Normal \\
\hline AS & $\mathrm{BS}+$ & KS & 60.55 & İyi & 145.87 & İyi & 172.12 & Kötü \\
\hline AS & $\mathrm{BS}+$ & $\mathrm{KS}+$ & 61.86 & İyi & 146.86 & İyi & 193.58 & Kötü \\
\hline AS & BS+ & KS- & 60.26 & Normal & 152.12 & Normal & 167.75 & Çok Kötü \\
\hline AS & BS- & KS & 60.73 & Normal & 145.87 & Normal & 182.22 & Normal \\
\hline AS & BS- & $\mathrm{KS}+$ & 61.77 & İyi & 141.94 & İyi & 183.95 & Normal \\
\hline AS & BS- & KS- & 60.25 & Normal & 138.34 & Normal & 181.04 & Kötü \\
\hline AS+ & BS & KS & 113.21 & İyi & 228.95 & İyi & 285.59 & İyi \\
\hline AS+ & BS & $\mathrm{KS}+$ & 106.93 & Çok İyi & 245.48 & Çok İyi & 302.06 & Çok İyi \\
\hline $\mathrm{AS}+$ & $\mathrm{BS}$ & KS- & 110.86 & Normal & 233.41 & Normal & 294.76 & Normal \\
\hline AS+ & $\mathrm{BS}+$ & KS & 123.25 & Çok İyi & 221.63 & Çok İyi & 410.96 & İyi \\
\hline $\mathrm{AS}+$ & $\mathrm{BS}+$ & $\mathrm{KS}+$ & 104.02 & Çok İyi & 225.75 & Çok İyi & 424.83 & Çok Kötü \\
\hline $\mathrm{AS}+$ & BS+ & KS- & 106.37 & İyi & 225.24 & İyi & 274.56 & İyi \\
\hline AS+ & BS- & KS & 107.82 & Normal & 219.52 & Normal & 278.69 & Normal \\
\hline $\mathrm{AS}+$ & BS- & $\mathrm{KS}+$ & 103.90 & İyi & 228.98 & İyi & 283.46 & İyi \\
\hline $\mathrm{AS}+$ & BS- & KS- & 90.56 & Normal & 223.32 & Normal & 282.49 & Normal \\
\hline AS- & BS & KS & 45.14 & Kötü & 104.22 & Kötü & 131.90 & Kötü \\
\hline AS- & BS & $\mathrm{KS}+$ & 46.12 & Normal & 107.29 & Normal & 135.04 & Normal \\
\hline AS- & BS & KS- & 44.85 & Normal & 99.24 & Kötü & 132.95 & Kötü \\
\hline AS- & $\mathrm{BS}+$ & $\mathrm{KS}$ & 44.35 & Normal & 100.43 & Normal & 132.27 & Normal \\
\hline AS- & $\mathrm{BS}+$ & $\mathrm{KS}+$ & 46.07 & İyi & 108.19 & İyi & 127.00 & Çok Kötü \\
\hline AS- & BS+ & KS- & 44.50 & Kötü & 99.49 & Kötü & 124.59 & Çok Kötü \\
\hline AS- & BS- & KS & 45.06 & Normal & 100.58 & Normal & 133.23 & Normal \\
\hline AS- & BS- & $\mathrm{KS}+$ & 47.04 & Kötü & 102.21 & Kötü & 133.13 & Normal \\
\hline AS- & BS- & KS- & 44.32 & Kötü & 103.20 & Normal & 138.97 & Kötü \\
\hline
\end{tabular}


Tablo 2. Verilen giriş görüntüleri için optimum parametre değerleri ve bunların tespit süreleri

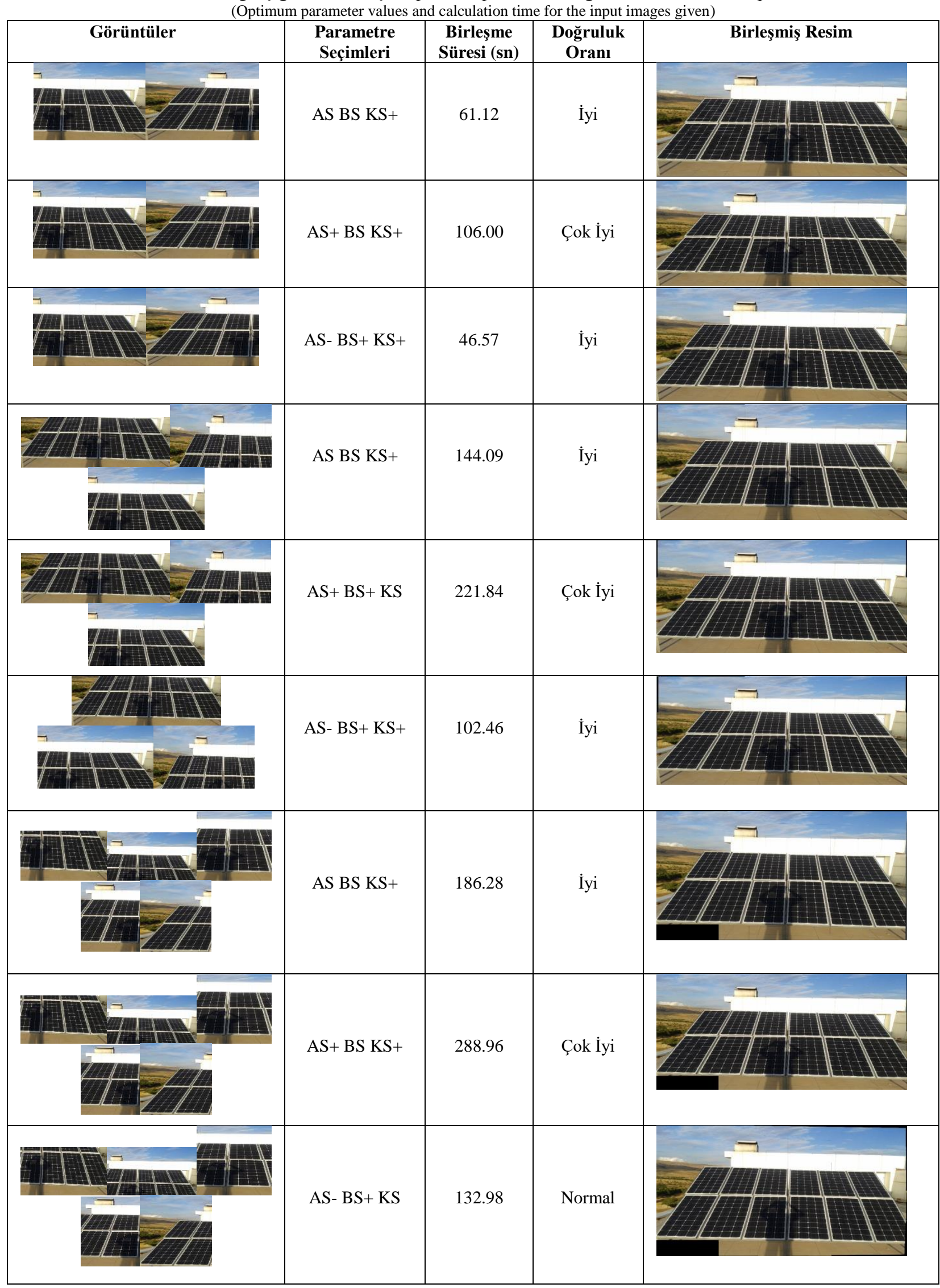


Tablo 3. Verilen video çerçeveleri için optimum parametre değerleri ve toplam birleştirme süreleri (Optimum parameter values and total mosaicing time for the frames of input video)

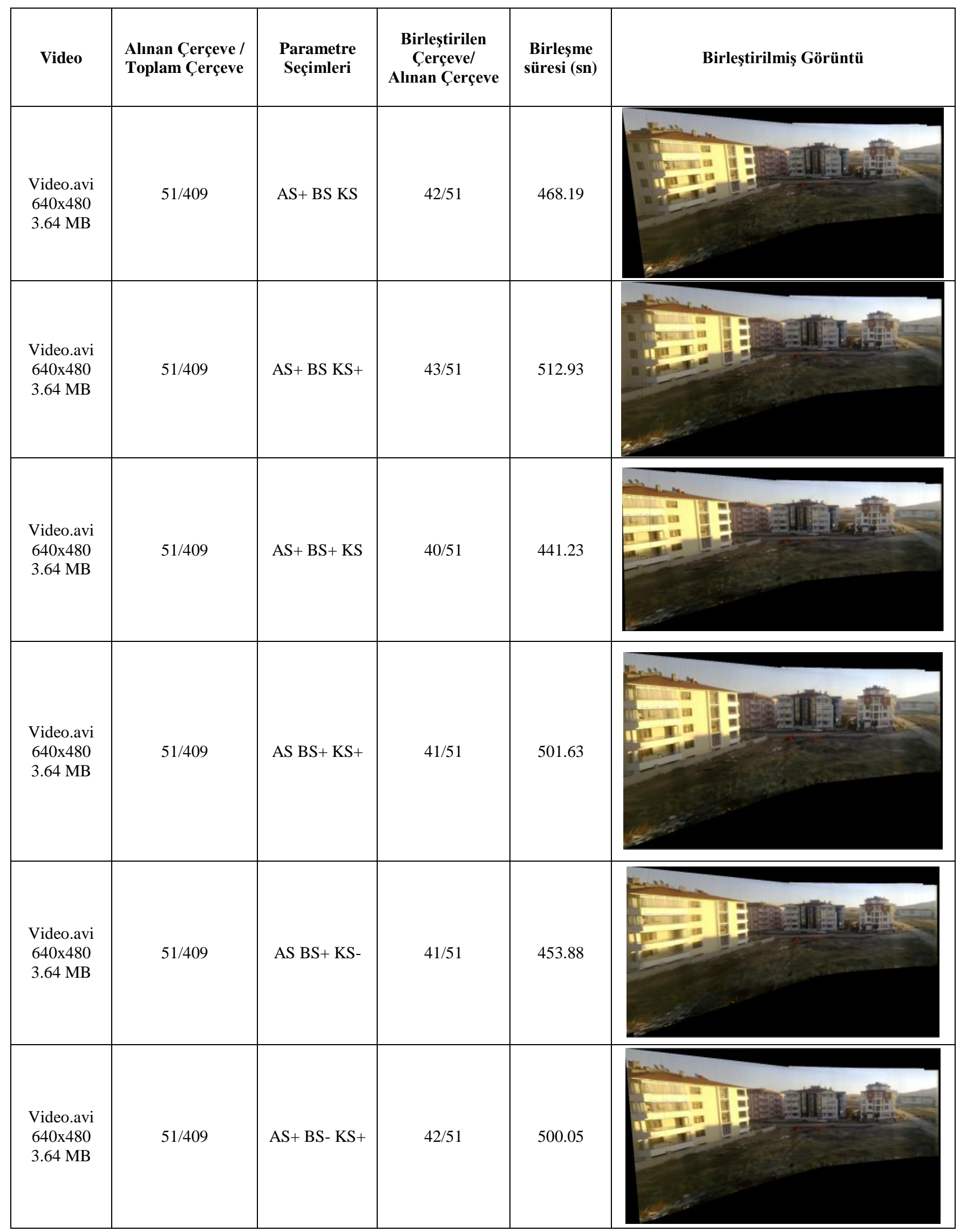


Tablolarda yer alan deneyler $2 \mathrm{GHz}$ Intel Core $2 \mathrm{CPU}, 4$ GB RAM ve Windows işletim sistemine sahip bilgisayar ile MATLAB ortamında gerçekleştirilmiştir. Tablo 1 incelendiğinde, 2,3 ve 5 görüntü içinde en kaliteli mozaikleme işleminin anahtar nokta sayısının yüksek tutulduğu durumlarda elde edildiği görülmektedir. Bu problemde her 3 görüntü için en iyi mozaikleme kalitesi anahtar nokta sayısı yüksek, benzerlik oranı normal ve küme merkezi sayısı yüksek olduğu durumda elde edilmiştir. Benzerlik oranının artırılması 5 görüntülü problemde kalitenin doğrudan düşmesine sebep olurken, benzerlik oranını artırırken küme sayısını azaltmanın durumu dengelemeye yönelik bir hareket olduğu görülmektedir. Anahtar nokta sayısının düşük, küme merkezi sayısı ve benzerlik oranının normal olduğu durumlarda ise mozaikleme işlemi en kötü sonucu vermektedir. Ayrıca tablodaki birleştirme süreleri incelendiğinde anahtar nokta sayısının, geçen süreyi doğrudan etkilediği görülmektedir. Geçen süreler göz önüne alındığında yöntemin gerçek zamanlı görüntü mozaikleme için uygun olmadığını göstermektedir. Verilen süreler daha iyi bir işlemci veya grafik birimi kullanarak daha da kisaltılabilir.

\section{SONUÇLAR (CONCLUSIONS)}

Görüntü mozaiklemede amaç, giriş görüntülerinin örtüşen sahnelerini üst üste düşürmektir. Bu çalışmada kendi kameramızdan elde ettiğimiz görüntüler üzerinde görüntü mozaikleme yöntemi uygulanmıştır. Gerçekleştirdiğimiz uygulamalarda MATLAB programı kullanılmıştır. Görüntü mozaikleme işlemindeki özellik tespiti adımında SIFT algoritmasından yararlanılmıştır. Uygulamada giriş görüntü sayıları farklı alınarak çeşitli karşılaştırmalar yapılmıştır. Yapılan karşılaştırmalar sonucunda, görüntü mozaikleme işleminde kullanılan anahtar nokta sayısı, benzerlik oranı ve küme merkezi sayısı parametrelerinin mozaikleme kalitesi üzerindeki etkisi incelenmiştir. Bu parametrelerin optimum değerlerinin belirlenmesi için genetik algoritmalardan yararlanan bir yöntem önerilmiştir.

Denemeler sonucunda anahtar nokta sayısının birleştirme işleminin süresini doğrudan etkilediği gözlemlenmiştir. Orta çözünürlükteki kameradan alınan ardışık video çerçeveleri geliştirilen yöntemden yararlanılarak mozaikleme işlemine tabi tutulmuştur. Bu işlem 40 çerçeve için yaklaşık 8 dakika sürmüştür. Yapılan çalışmalar sonucunda en iyi mozaikleme sonucunu veren parametreler tespit edilmiş ve dolayısıyla mozaiklenen görüntünün kalitesinin artması sağlanmıştır. Gerçek zamanlı olarak kullanımı uygun olmayan yöntem, sinema veya fotoğrafçılık gibi kalitedeki artışın geçen süreden daha önemli olduğu alanlarda kullanılabilir. Birleştirme işleminin süresinin kısaltılmasına yönelik çalışmalar, ilerde yapılması öngörülen çalışmalardandır.

\section{TEŞEKKÜR (ACKNOWLEDGMENT)}

$\mathrm{Bu}$ çalışma Türkiye Bilimsel ve Teknolojik Araştırma Kurumu (TUBITAK) tarafından TÜBİTAK 1001 programı kapsamındaki 112E214 numaralı proje ile desteklenmiştir.

\section{KAYNAKLAR (REFERENCES)}

[1] C. Tastimur, H. Yetis, M. Karakose, E. Akın, "Rail Defect Detection and Classification with Real Time Image Processing Technique", International Journal of Computer Science and Software Engineering (IJCSSE), 5(12), Aralık, 2016

[2] Y. Santur, M. Karakose, E. Akın, "Learning Based Experimental Approach for Condition Monitoring Using Laser Cameras in Railway Tracks", International Journal of Applied Mathematics, Electronics and Computers, 4(s1), 1-5, Eylül, 2016.

[3] D. Ghosh, N. Kaabouch, "A Survey on Image Mosaicing Techniques", Journal of Visual Communication and Image Representation, 32, 1-11, 2016.

[4] M. Lin, G. Xu, X. Ren, K. Xu, "Cylindrical Panoramic Image Stitching Method Based On Multi-cameras", The $5^{\text {th }}$ Annual IEEE International Conference on Cyber Technology in Automation, Control and Intelligent Systems, Shenyang, China, 1091-1096, Haziran, 2015.

[5] G. Divya, C. Chandrasekhar, "Image Mosaicing Technique for Wide Angle Panorama", TELKOMNIKA Indonesian Journal of Electrical Engineering, 15, 420-429, 2015

[6] A. Elibol, J. Kim, N. Gracias, "Fast Underwater Image Mosaicing through Submapping”, Journal of Intelligent \& Robotic Systems, 1-21, 2016.

[7] M. S. Patel, N. M. Patel, M. S. Holia, "Feature Based Multi-view Image Registration using SURF", International Symposium on Advanced Computing and Communication (ISACC), Silchar, India, 213-218, Eylül, 2015.

[8] M. U. Akram, D. Usmani, T. Ahmad, S. Abbas, S. F. Noor, "Seamless Fundus Image Stitching using WLD to Improve Field of View", 5th International Conference on Digital Information and Communication Technology and its Applications (DICTAP), Beirut, Lübnan, 106-110, Nisan, 2015.

[9] R. Abraham, P. Simon, "Review on Mosaicing Techniques in Image Processing”, International Conference on Advanced Computing \& Communication Technologies, Rohtak, India, 63-68, Nisan, 2013

[10] C. M. Huang, S. W. Lin, J. H. Chen, "Efficient Image Stitching of Continuous Image Sequence with Image and Seam Selections", IEEE Sensors Journal, 15, 5910-5918, 2015.

[11] S. Lee, Y. Park, D. Lee, "Seamless Image Stitching Using Structure Deformation with HoG Matching", International Conference on Information and Communication Technology Convergence (ICTC), Jeju, South Korea, 933-935, Ekim, 2015.

[12] Z. Qui, P. Shi, X. Jiang, D. Pan, C. Feng, Y. Sha, "Image Stitching and Ghost Elimination Based on Shape-Preserving Half-Projective Warps", International Conference on Information and Automation, Lijiang, China, 2610-2615, Ağustos, 2015.

[13] A. Laraqui, A. Baataoui, A. Saaidi, A. Jarrar, M. Masrar, K. Satori, "Image mosaicing using voronoi diagram", Multimedia Tools and Applications, 1-27, 2016.

[14] H. Yetiş, M. Baygin, M. Karakose "A New Micro Genetic Algorithm Based Image Stitching Approach for Camera Arrays at Production Lines", The 5th International Conference on Manufacturing Engineering and Process (ICMEP 2016), İstanbul, Mayıs, 2016. 
[15] H. Li, B. S. Manjunath, S. K. Mitra, "Multisensor image fusion using wavelet transform", Graphical Models Image Process, 57(3), 235 245, 1995.

[16] W.W. Kong, Y.J. Lei, Y. Lei, S. Lu, "Image fusion technique based on non-subsampled contour let transform and adaptive unit-fast-linking pulse-coupled neural network", IET Image Process, 5(2), 113-121, 2011.

[17] H. Yetis, M. Karakose, "Adaptive Vision Based Condition Monitoring and Fault Detection Method for Multi Robots at Production Lines in Industrial Systems", International Journal of Applied Mathematics, Electronics and Computers (IJAMEC), 4(1), 271-276, 2016

[18] P. M. Jain, V. K. Shandliya, "A Review Paper on Various Approaches for Image Mosaicing", International Journal of Computational Engineering Research, 3, 106-109, 2013.

[19] P. M. Panchall, S. R. Panchal, K. Shah, "A Comparison of SIFT and SURF", International Journal of Innovative Research in Computer and Communication Engineering, 1(2), Nisan, 2013.

[20] H. Joshi, K. Sinha, "A Survey on Image Mosaicing Techniques", International Journal of Advanced Research in Computer Engineering \& Technology (IJARCET), 2, 365-369, 2013.

[21] I.K. Sarangi, S. Nayak, Image Mosaicing of Panoramic Images, Bachelor Thesis, National Institute of Technology, Rourkela.

[22] Z. Yu, H. Zhang, B. Guo, L. Zhu, "A Mosaic Method for Large Perspective Distortion Image", Intemational Conference on Measurement, Information and Control, 2012.

[23] J. Qin, J. Yang, B. Xue , F. Bu, "Research on Image Registration and Mosaic Basedon Vector Similarity Matching Principle", Fifth International Symposium on Computational Intelligence and Design, 2012

[24] S. M. Smith, J. M. Brady, "SUSAN a new approach to low-level image processing", International Journal of Computer Vision, 23(1), 4578, 1997
[25] X. Jing, Y. X. Hong, S. X. Xin, M. X. Ying, "Medical Image Mosaic Technology Based on Image Phase Correlation", Fourth International Conference on Digital Home, 2012.

[26] L. Kitchen, A. Rosenfeld, "Gray level corner detection," Pattern Recognition Letters, 95-102, 1982.

[27] V. S. Bind, Robust Techniques for Feature-based Image Mosaicing, Thesis of the requirements for the degree of Master, 2013.

[28] M. R. Jahanshahi, S. F. Masri, G. S. Sukhatme, "Multi-Image Stitching and Scene Reconstruction for Evaluating Defect Evolution in Structures", Structural Health Monitoring, 643-657, 2011.

[29] M. Huang, Z. C. Mu, H. Zeng, H. Huang, “A Novel Approach for Interest Point Detection via Laplacian-of-Bilateral Filter", Journal of Sensors, 1(9), Mart, 2015

[30] T. Muezzinoglu, F. Colak, M. Karakose, "Görüntü Mozaikleme Algoritması İçin Deneysel Bir Çalıșma”, Fırat Üniv. Mühendislik Bilimleri Dergisi, 26(1), 17-25, 2014.

[31] D. G. Lowe, "Distinctive Image Features from Scale-Invirant Keypoints", International Journal of Computer Vision, 2004

[32] V. Aslantaş, E. Bendes, R. Kurban, A. N. Toprak, "Coklu Algılayıcılardan Alınan Görüntülerde Eşleştirme Yöntemlerinin Karşılaştırılması”, Elektrik-Elektronik ve Bilgisayar Sempozyumu, 110-114, 2011.

[33] S. Mistry, A. Patel, "Image Stitching using Harris Feature Detection", International Research Journal of Engineering and Technology (IRJET), 3, 1363-1369, 2016.

[34] A. Levin, A. Zomet, S. Peleg, Y. Weiss, "Seamless Image Stitching in the Gradient Domain”, Computer Vision (ECCV), 377-389, 2004 